\title{
Labor-Leisure Choice: Is Everything as Straightforward as One Might Have Thought?
}

\author{
Emin Gahramanov ${ }^{1}$, Xueli Tang ${ }^{2}$ \\ ${ }^{1}$ American University of Sharjah, Sharjah, United Arab Emirates \\ ${ }^{2}$ Deakin University, Melbourne, Australia \\ Email:xueli.tang@deakin.edu.au
}

Received 3 July 2016; accepted 8 August 2016; published 11 August 2016

Copyright (C) 2016 by authors and Scientific Research Publishing Inc.

This work is licensed under the Creative Commons Attribution International License (CC BY). http://creativecommons.org/licenses/by/4.0/

c) (i) Open Access

\begin{abstract}
We argue that a full understanding of a rational labor supply choice in a standard dynamic life cycle framework is obscure, despite the framework's being seemingly self-explanatory, straightforward, and intuitively sensible. In a completely friction-free environment, we, to our knowledge, are the first to provide a complete analytic solution to the benchmark model that presumes a kind of labor supply behavior that is typically taken as the standard in economic studies. We find that such standard behavior holds only for a narrow set of parameters. For many alternative parameterizations, the labor supply behavior of a rational agent is either highly unrealistic, or extremely hard to predict and interpret. A complete understanding of a rational, intertemporal labor supply choice requires further analysis.
\end{abstract}

\section{Keywords}

Life-Cycle Consumption and Labor Supply, Constrained Optimal Control

\section{Introduction}

The benchmark neoclassical life-cycle model of labor supply and consumption/saving was developed by [1], and later revisited by [2]. Yet the authors and many subsequent studies focused only on an interior solution for the optimal labor/leisure choice. In this paper, we focus on some fundamental issues that have been overlooked when focusing on such solutions.

First, in reality the time constraint on leisure does bind (i.e., individuals do quit the labor force). Thus the model is yet to answer what rational labor supply behavior should be in theory when the constraint is active, 
which is likely to become relevant once a full spectrum of the model's parameters is considered. It might be that what contemporary studies find confusing in labor market behavior is actually perfectly natural, and hence various criticisms of intertemporal labor supply frameworks might have been overstated. ${ }^{1}$ Second, quantitativetheoretical models typically consider parameterization under which a representative agent in a frictionless environment always works non-stop right after he enters the model, before permanently retiring at a reasonably senior age. For the sake of convenience, we call that type of behavior "standard". Yet so far, to our knowledge, neither [1] nor closely-related studies have systematically analyzed such a standard behavior via conventional mathematical techniques. We believe that this was done to simplify the mathematics involved. Indeed, researchers who work closely on optimal control problems know that inequality constraints in even relatively simple settings make the analytical solution to these problems very difficult, sometimes even impossible, to obtain (see, e.g., [6]). However, we wondered whether simplifying the solutions of the model threw the baby out with the bathwater.

Hence, it is also unclear how easy it is to obtain the standard behavior in a typical labor-leisure choice framework. In addition and importantly, it is not at all clear whether very "non-standard" labor supply patterns can arise even in a totally frictionless economic setting when the time constraint on leisure binds, urging, for instance, the agent to quit and re-enter the labor force multiple times.

In this study, we use optimal control theory to explicitly provide a complete analytic solution to the benchmark model, which gives rise to the standard labor supply behavior. We use the benchmark model à la [1] and [2] as the foundation of our analysis because the model straightforwardly and elegantly describes the intertemporal choice in a high-frequency setting. The model is also convenient to use because it can be naturally framed within continuous time optimal control theory. The latter is a well-developed, carefully researched, and leading branch of mathematics, ${ }^{2}$ so we rely on it during our solution exercise.

We thus assume a rational individual who has well-defined, standard preferences over labor/leisure and consumption and is also aware of his/her survival chances. The agent is far-sighted and uses all available information to consider his lifetime resources (given wage income and potential interest earnings) to optimally choose the lifetime paths of consumption/saving and labor/leisure. The agent thus decides both on how many hours to work when employed and on the timing of exiting the workforce. Whatever is not consumed out of wage income helps boost the agent's asset account. We deliberately keep the environment simple and totally friction-free.

Upon solving the model, we find that the standard labor supply behavior holds for a very limited range of the model parameters. For other parameters, we observe that either the agent never retires (time endowment constraint never binds), or retires unrealistically late in life. One can certainly think of various extensions of the model and additional assumptions (e.g., rapidly declining health status with age) that might cause the agent to retire much earlier in life. However, to what extent such assumptions are both helpful and realistic is a question future research should shed some light on.

Even more alarming, we find that under many sensible parameters, the labor supply behavior is not standard and cannot be straightforwardly determined from the analytic standpoint. We thus proceed by applying numerical software to the model. Doing so confirms our analytic suspicion that for those alternative parameters, the labor supply choice gets very confusing, and very hard to interpret intuitively a priori. For example, despite the absence of any friction or behavioral defects, rational agents often decide to frequently enter/exit the labor market, while frequently displaying prolonged voluntary absenteeism from work (sometimes spanning for a few decades), thus being completely at odds with intuition. In fact, non-standard labor supply behavior often arises for our model's preference parameters identified as realistic in various micro studies. There is an enormous amount of literature on consumption smoothing and related topics, and perhaps it is time to investigate how smooth and predictable labor supply behavior can be.

We would like to emphasize that not knowing the root causes of remaining out of a job may bias policy analysis. Let us consider maternity-related career breaks as an example. Can we argue that historically, many females have exited the labor force because of a genuine maternal reason or because having a child is a legitimate and financially more attractive option to retain the job and the benefits while being away from work, with the latter being the main driving force? For the sake of an argument, let us suppose that childbearing motives are

\footnotetext{
${ }^{1}$ Some of the so-called paradoxes identified in the literature include the tendency of many workers to stop working until an overtime premium begins [3], the tendency of taxi drivers not to work more hours when customers are plentiful [4], a negative effect of a decrease in wealthy husbands' incomes on some women's labor force participation [5], etc.

${ }^{2}$ Further to this, ([7], p. 65]) and ([8], p. 411]) provide examples of the importance of continuous time models in various economic applications involving intertemporal consumption/savings choice.
} 
rather weak to start with and that a person is not really inclined to interrupt her employment at a young age. In this example, many typical proposals encouraging maternity leave would be inefficient. Alternatively, can we say that many people who remain unemployed for years are as such primarily because of existing structural problems in the economy (e.g., poor public education that makes young people unproductive, artificial scarcity created by non-competitive economic sectors) or primarily because such a behavior naturally follows from people's intertemporal optimization exercise? Thus, a complete understanding of a rational, intertemporal labor supply choice even in a seemingly straightforward, totally friction-free environment requires further in-depth analysis.

We would like to acknowledge that, based on Heckman's benchmark model, most contemporary quantitative-theoretical studies introduce sophisticated and realistic assumptions. Such models are plentiful in the areas of real-business-cycle fluctuations, public pensions, and so on. However, our point in this study is not to argue against the augmentation of Heckman's framework (or to downgrade the importance of new assumptions and features found in the more recent literature) but to show that very puzzling and unexpected labor supply patterns are likely to arise even in a model that is totally straightforward and friction-free. We thus have plausible reasons to suspect that many existing labor/leisure models in quantitative-theoretical studies, however sophisticated, have yet to answer the same questions that confront the stylized benchmark model à la [1] [2] when a full spectrum of parameters is considered in those studies. In other words, predicting how the labor supply of various individuals will react to policy changes and modeling assumptions may not be as straightforward and easy as one might have assumed. We thus hope to stimulate future research to deeply investigate intertemporal labor supply behavior.

In what follows, Section 2 provides brief literature review. Section 3 presents a basic traditional model, while Sections 3.1 and 3.2 present analytic solutions. Section 4 presents numerical results based on the analytic derivations, while Section 5 briefly summarizes the results generated by the numerical software. The last section presents the conclusion.

\section{Literature Review}

Many empirical and experimental studies identify various reasons that may induce people to interrupt their careers (see, e.g., [9]-[16]; and the references therein). Furthermore, voluminous empirical literature investigates the phenomenon of labor force participation across countries, demographic groups, and professions. For instance, the study by [17] provides evidence that dropping out of the labor force is particularly relevant for women, single mothers, and some less-educated segments of the population, but the conclusions significantly vary for urban and rural females.

Many other studies apply a variant of the benchmark life-cycle labor/leisure choice model to examine a wide range of policy-relevant questions. To our knowledge, however, none of these studies identify a nonstandard labor supply path as a potential issue. For instance, [18] models a standard labor supply structure and investigates different labor types in production and how their elasticity of substitution affects the outcome of social security and tax reforms. The study of [19] analyzes the macroeconomic and welfare effects of ending mandatory retirement within a life-cycle environment where lifetime is divided between working and retirement periods. In general, studies that use a similar labor supply structure in analyzing important issues, such as pension reforms, taxation, aging, and fertility, or studies that assume a clear career interruption channel are not scant (see, e.g., [20]-[22]).

Hence, a common feature of these studies is that they either assume an obvious cause that triggers an employment cessation (e.g., quitting work to take care of one's family members), or they simply parameterize a model in a way that generates an exit from the labor force when the agent is reasonably old. However, let us suppose that no friction or behavioral defect exists within an economy, nor does an obvious reason to induce one to cease employment. Can we say that for one to have incentive to apply, for example, for an unpaid leave, a legitimate reason (e.g., a maternity-related one) must exist? If the answer is no, is it then the case in reality that people invent a reason just to be granted permission to leave and take a break from work while ensuring that their job remains open for them? Can a researcher be sure that people would necessarily choose smooth labor supply paths and exit the labor force at old ages when very little can be earned even if they stay employed? Simply put, do people always desire to work when one expects them to? Further to this, if the life-cycle consumption path is relatively smooth and sensible, is it possible for the corresponding labor supply path to be nonsmooth and confusing? Can it be said that many jobless people fail to restart employment because few oppor- 
tunities are open for them or because such behavior simply reflects their preferences and intertemporal optimization decisions even in a totally friction-free environment? By simplifying the analytical solutions to intertemporal labor/leisure choice models and assuming $a$ priori how a "reasonable" lifetime labor supply path should be, existing literature has overlooked such questions. In this short study, we are unable to adequately answer all the above questions. However, we believe that the surprising findings we have generated should be interesting enough to stimulate future research that will deeply investigate intertemporal labor supply behavior and perhaps completely reconsider the baseline choice framework based on which many more assumptions are introduced in various contemporary studies.

\section{Model: Basic Setup}

Following [1] and [2], time is continuous and denoted by $t$. The agent enters the workforce at birth $(t=0)$. Let $Q(t)$ denote the probability of surviving until age $t$, which is a strictly positive and decreasing $C^{1}$ function. The individual definitely exits the model by age $t=T>0$. A market-determined constant wage per labor efficiency unit $(\epsilon(t))$, is $w$. All wage income not consumed flows into the individual financial asset account $k(t)$, which grows at the rate, $r$. The individual starts the life cycle with no assets, and if he survives till age $T$, he finishes the life cycle with no assets either. Preferences over consumption and leisure are given by

$$
U(c(t), l(t))=\left\{\begin{array}{l}
\frac{\left(c(t)^{\phi} l(t)^{1-\phi}\right)^{1-\sigma}}{1-\sigma} \text { for } \sigma \neq 1 \\
\phi \ln (c(t))+(1-\phi) \ln (l(t)) \text { for } \sigma=1
\end{array},\right.
$$

where $\sigma>0$ is the parameter of the inverse elasticity of intertemporal substitution, and $0<\phi<1$ captures the trade-off between leisure and consumption. Time endowment is normalized to unity.

\subsection{Our Solution: The Constrained Control Problem}

Let the rate of time preference be denoted by $\rho$. The agent's problem is to

$$
\operatorname{Max}_{\{c(t), l(t)\}} \int_{0}^{T} Q(t) \mathrm{e}^{-\rho t} U(c(t), l(t)) \mathrm{d} t
$$

subject to the budget equation, control region, and the end-point conditions, given in (3)-(6):

$$
\begin{gathered}
\frac{\mathrm{d} k(t)}{\mathrm{d} t}=r k(t)+ \\
w \epsilon(t)(1-l(t))-c(t), \\
l(t) \leq 1, \\
k(0)=0, \\
k(T)=0 .
\end{gathered}
$$

Remark 1. [1], [2] and closely-related studies ignored constraint (4).

We thus define the Hamiltonian function

$$
H_{1}=Q(t) \mathrm{e}^{-\rho t} \frac{\left(c(t)^{\phi} l(t)^{1-\phi}\right)^{1-\sigma}}{1-\sigma}+\mu(t)(r k(t)+w \epsilon(t)(1-l(t))-c(t)),
$$

where $\mu(t)$ is a time-varying multiplier.

Optimal controls must be chosen so the following conditions are satisfied: ${ }^{3}$

$$
\begin{gathered}
\frac{\mathrm{d} k(t)}{\mathrm{d} t}=\frac{\partial H_{1}}{\partial \mu(t)}=r k(t)+w \epsilon(t)(1-l(t))-c(t), \\
\frac{\mathrm{d} \mu(t)}{\mathrm{d} t}=-\frac{\partial H_{1}}{\partial k(t)}=-\mu(t) r,
\end{gathered}
$$

\footnotetext{
${ }^{3} \mathrm{~A}$ reader may refer, for instance, to [6], or any standard book on deterministic optimal control.
} 
and

$$
\max _{\{1-l(t) \geq 0, c(t)\}} H_{1} \Leftrightarrow \max _{\{1-l(t) \geq 0, c(t))\}}\left\{H_{2}=Q(t) \mathrm{e}^{-\rho t} \frac{\left(c(t)^{\phi} l(t)^{1-\phi}\right)^{1-\sigma}}{1-\sigma}+\mu(t)(w \epsilon(t)(1-l(t))-c(t))\right\} .
$$

A necessary condition is that there exists a time-dependent multiplier $\lambda(t) \leq 0$, so that if the Lagrangian of the Hamiltonian

$$
H=Q(t) \mathrm{e}^{-\rho t} \frac{\left(c(t)^{\phi} l(t)^{1-\phi}\right)^{1-\sigma}}{1-\sigma}+\mu(t)(w \epsilon(t)(1-l(t))-c(t))+\lambda(t)(l(t)-1),
$$

then the following conditions are satisfied:

$$
\begin{gathered}
\frac{\partial H}{\partial c(t)}=Q(t) \phi \mathrm{e}^{-\rho t} c(t)^{\phi(1-\sigma)-1} l(t)^{(1-\phi)(1-\sigma)}-\mu(t)=0, \\
\frac{\partial H}{\partial l(t)}=Q(t)(1-\phi) \mathrm{e}^{-\rho t} c(t)^{\phi(1-\sigma)} l(t)^{\phi(\sigma-1)-\sigma}-\mu(t) w \epsilon(t)+\lambda(t)=0, \\
\lambda(t)(l(t)-1)=0, \\
1-l(t) \geq 0 .
\end{gathered}
$$

Let us make a hypothesis that the structure of the solution is consistent with the standard behavior. Let there be some internal point in time (switching time) $t^{*} \in(0, T)$ (to be determined) on and after which the agent completely stops working, and hence optimal leisure is $l(t)=1$. Thus,

$$
\begin{aligned}
& l(t)<1 \text { for } t \in\left[0, t^{*}\right), \\
& l(t)=1 \text { for } t \in\left[t^{*}, T\right] .
\end{aligned}
$$

A complementarity condition implies that if $\lambda(t)=0$, then $l(t)<1$, and we have the system of equations

$$
\left(\begin{array}{c}
k(t) \\
\mu(t)
\end{array}\right)^{\prime}=\left(\begin{array}{c}
r k(t)+w \epsilon(t)(1-l(t))-c(t) \\
-\mu(t) r
\end{array}\right) \text { for } t \in\left[0, t^{*}\right) .
$$

Similarly, if $\lambda(t)<0$, then $l(t)=1$, and we have the system of differential equations

$$
\left(\begin{array}{c}
k(t) \\
\mu(t)
\end{array}\right)^{\prime}=\left(\begin{array}{c}
r k(t)-c(t) \\
-\mu(t) r
\end{array}\right) \text { for } t \in\left[t^{*}, T\right]
$$

Hence, the solution to the problem can be found by piecing together the solution of (18) and (19). In doing so, we first note the multiplier function $\mu(t)$ is defined over the entire region $t \in[0, T]$, and from (18) and (19) it clearly obeys the same law of motion on each subarc. Since the function is required to be continuous, we get

$$
\mu(t)=a \mathrm{e}^{-r t} \text { for } t \in[0, T]
$$

where $a$ is a constant to be determined.

From (12) we deduce that

$$
c(t)=\left((1 /(\phi Q(t))) \mathrm{e}^{\rho t} l(t)^{(1-\sigma)(\phi-1)} \mu(t)\right)^{\frac{1}{\phi(1-\sigma)-1}} .
$$

Now, note that if $\lambda(t)=0$, then $l(t)<1$, meaning that (21), being substituted into (13), would result in

$$
\mu(t)=a \mathrm{e}^{-r t}=Q(t)(1-\phi)^{1+\phi(\sigma-1)} \phi^{\phi(1-\sigma)} e^{-\rho t} l(t)^{-\sigma}(1 /(w \epsilon(t)))^{1+\phi(\sigma-1)} .
$$

Recall that $l\left(t^{*}\right)=1$. Using this in (22), we can express the constant $a$ in terms of $t^{*}$ as follows 


$$
a \equiv a\left(t^{*}\right)=Q\left(t^{*}\right) \mathrm{e}^{(r-\rho) t^{*}}(1-\phi)^{1+\phi(\sigma-1)} \phi^{\phi(1-\sigma)}\left(1 /\left(w \epsilon\left(t^{*}\right)\right)\right)^{1+\phi(\sigma-1)} .
$$

Thus,

$$
\mu(t)=a\left(t^{*}\right) \mathrm{e}^{-r t} \text { for } t \in[0, T] .
$$

Substituting (24) into (21) and recalling that $l(t)=1$ if $\lambda(t)<0$, we deduce from (19) that

for $t \in\left[t^{*}, T\right]$.

$$
\frac{\mathrm{d} k(t)}{\mathrm{d} t}=r k(t)-\mathrm{e}^{\frac{\rho-r}{\phi(1-\sigma)-1}}\left((1 /(\phi Q(t))) a\left(t^{*}\right)\right)^{\frac{1}{\phi(1-\sigma)-1}},
$$

Using the boundary condition (6), we find the solution to (25) as

$$
k(t)=\mathrm{e}^{r t}\left(a\left(t^{*}\right) / \phi\right)^{\frac{1}{\phi(1-\sigma)-1}} \int_{t}^{T}\left((1 / Q(u)) \mathrm{e}^{(\phi r(\sigma-1)+\rho) u}\right)^{\frac{1}{\phi(1-\sigma)-1}} \mathrm{~d} u,
$$

for $t \in\left[t^{*}, T\right]$.

Evaluating (26) at $t=t^{*}$, we obtain

$$
k\left(t^{*}\right) \equiv \Lambda_{1}\left(t^{*}\right)=\mathrm{e}^{r t^{*}}\left(a\left(t^{*}\right) / \phi\right)^{\frac{1}{\phi(1-\sigma)-1}} \int_{t^{*}}^{T}\left((1 / Q(t)) \mathrm{e}^{(\phi r(\sigma-1)+\rho) t}\right)^{\frac{1}{\phi(1-\sigma)-1}} \mathrm{~d} t .
$$

Next, substituting (24) into (12) and (13) and considering the $\lambda(t)=0$ case, we solve for the time-dependent consumption and leisure paths as functions of $t^{*}$ as follows

$$
\begin{aligned}
& c(t)=a\left(t^{*}\right)^{-\frac{1}{\sigma}} \Omega_{1}(t), \\
& l(t)=a\left(t^{*}\right)^{-\frac{1}{\sigma}} \Omega_{2}(t),
\end{aligned}
$$

for $t \in\left[0, t^{*}\right)$. Here

$$
\begin{gathered}
\Omega_{1}(t) \equiv Q(t)^{\frac{1}{\sigma}}(1-\phi)^{\frac{(\sigma-1)(\phi-1)}{\sigma}} \phi^{\frac{\sigma+\phi(1-\sigma)}{\sigma}} w^{\frac{(\sigma-1)(1-\phi)}{\sigma}} \epsilon(t)^{\frac{(\sigma-1)(1-\phi)}{\sigma}} \mathrm{e}^{\frac{r-\rho}{\sigma} t}, \\
\Omega_{2}(t) \equiv Q(t)^{\frac{1}{\sigma}}(1-\phi)^{\frac{1+(\sigma-1) \phi}{\sigma}} \phi^{\frac{\phi(1-\sigma)}{\sigma}} w^{\frac{\phi(1-\sigma)-1}{\sigma}} \epsilon(t)^{\frac{\phi(1-\sigma)-1}{\sigma}} \mathrm{e}^{\frac{r-\rho}{\sigma} t} .
\end{gathered}
$$

Substituting (28) and (29) into (18), we obtain

$$
\frac{\mathrm{d} k(t)}{\mathrm{d} t}=r k(t)+w \epsilon(t)\left(1-a\left(t^{*}\right)^{-\frac{1}{\sigma}} \Omega_{2}(t)\right)-a\left(t^{*}\right)^{-\frac{1}{\sigma}} \Omega_{1}(t),
$$

for $t \in\left[0, t^{*}\right)$.

Using (5), we solve (32) as

$$
k(t)=\mathrm{e}^{r t} \int_{0}^{t}\left(w \epsilon(u)\left(1-a\left(t^{*}\right)^{-\frac{1}{\sigma}} \Omega_{2}(u)\right)-a\left(t^{*}\right)^{-\frac{1}{\sigma}} \Omega_{1}(u)\right) \mathrm{e}^{-r u} \mathrm{~d} u,
$$

for $t \in\left[0, t^{*}\right)$.

Because of the required continuity of $k(t)$, we obtain from (33)

$$
k\left(t^{*}\right) \equiv \Lambda_{2}\left(t^{*}\right)=\mathrm{e}^{r t^{*}} \int_{0}^{t^{*}}\left(w \epsilon(t)\left(1-a\left(t^{*}\right)^{-\frac{1}{\sigma}} \Omega_{2}(t)\right)-a\left(t^{*}\right)^{-\frac{1}{\sigma}} \Omega_{1}(t)\right) \mathrm{e}^{-r t} \mathrm{~d} t .
$$

Hence, $t^{*}$ is the solution to the following equation

$$
\Lambda_{1}\left(t^{*}\right)=\Lambda_{2}\left(t^{*}\right)
$$

Let "RHS" stand for "the right-hand-side" expression. We then summarize the solution to problem (2)-(6) for 
this section as

$$
\begin{gathered}
k(t)=\left\{\begin{array}{l}
\text { RHS of Eq. (33) for } t \in\left[0, t^{*}\right) \\
\text { RHS of Eq. (26) for } t \in\left[t^{*}, T\right]
\end{array}\right. \\
c(t)=\left\{\begin{array}{l}
\text { RHS of Eq. (28) for } t \in\left[0, t^{*}\right) \\
\mathrm{e}^{\frac{\rho-r}{\phi(1-\sigma)-1} t}\left((1 /(\phi Q(t))) a\left(t^{*}\right)\right)^{\frac{1}{\phi(1-\sigma)-1}} \text { for } t \in\left[t^{*}, T\right]
\end{array}\right. \\
l(t)=\left\{\begin{array}{l}
\text { RHS of Eq. }(29) \text { for } t \in\left[0, t^{*}\right) \\
1 \text { for } t \in\left[t^{*}, T\right]
\end{array}\right.
\end{gathered}
$$

where $t^{*}$ solves (35), the costate variable is determined from (24), and $\lambda(t)$ is found from (13).

\subsection{A Typical, Heckman/Bütler-Type Solution: An Unconstrained Control Problem}

Let us consider the Heckman/Bütler-type solution where the constraint on leisure is inactive. This would lead to the following optimal solutions for the consumption, leisure, and capital account paths, given respectively by (39)-(41).

$$
\begin{gathered}
c_{u n}(t)=b^{-\frac{1}{\sigma}} \Omega_{1}(t), \\
l_{u n}(t)=b^{-\frac{1}{\sigma}} \Omega_{2}(t), \\
k_{u n}(t)=\mathrm{e}^{r t} \int_{0}^{t}\left(w \epsilon(u)\left(1-l_{u n}(u)\right)-c_{u n}(u)\right) \mathrm{e}^{-r u} \mathrm{~d} u,
\end{gathered}
$$

for $t \in[0, T]$, where the subscript "un" stands for "unconstrained" optimization, $\Omega_{1}(t), \Omega_{2}(t)$ are defined earlier, and ${ }^{4}$

$$
b^{-\frac{1}{\sigma}}=\frac{\int_{0}^{T} \mathrm{e}^{-r t} w \epsilon(t) \mathrm{d} t}{\int_{0}^{T} \mathrm{e}^{-r t}\left(w \epsilon(t) \Omega_{2}(t)+\Omega_{1}(t)\right) \mathrm{d} t} .
$$

\section{Numerical Results Based on Analytic Derivations}

We assume the maximum life length is 100 years as mortality data based on the U.S. life tables were top cut at age 100 [23]. We set our survival probability $Q(t)$ to [23]'s sextic polynomial, and set efficiency profile $\epsilon(t)$ to the author's quartic polynomial, yet forcing the latter to keep steadily decaying (since [23]'s polynomial picks up in old ages). As we model agents from age 25 onward, we set $T=75$. Various quantitative-theoretical life-cycle studies (e.g., [24]-[26]), replicating some key steady-state targets in the U.S. economy, often compute the equilibrium wage rate to be in the vicinity of 1 , so we set $w=1$. We set $r=0.035$, which is a reasonable rate for a yearly risk-free return. Since calibrated macroeconomic models justify the discount rate of about 3\% per annum, or sometimes even slightly negative (see, e.g., [20]; [23]; [24]), we vary $\rho$ from 1 to 3 percent per annum. The literature typically considers a much wider range for the elasticity parameter $\sigma$ (see, e.g., [27]; [28]) so we vary that parameter from 0.5 to 10 .

Our numerical experiments are presented in Tables 1-3. The numerical entries (retirement ages under standard behavior) in the tables are rounded up to the nearest integer for the ease of illustration. " $n b$ " means the time constraint never binds, i.e., the agent never retires. "?” means the labor supply behavior is yet to be determined and is likely to feature multiple switching points, and/or some pronounced absenteeism from the job market.

Remark 2. Many parameters result in the agent working non-stop all his life (solutions (39)-(41) i.e., " $n b$ ”). For other parameters, the agent manages to retire but extremely late in life. And only a couple of realistic retirement ${ }^{4}$ The proof of these results is quite tedious, yet straightforward, and thus we omit them here for the sake of brevity. They can be found in a technical appendix available upon request. 
Table 1. Labor supply choice $(\rho=1 \%)$.

\begin{tabular}{ccccccccccc}
\hline$\sigma / \varphi$ & 0.1 & 0.2 & 0.3 & 0.4 & 0.5 & 0.6 & 0.7 & 0.8 & 0.9 \\
\hline 0.5 & $?$ & $?$ & $?$ & $?$ & $?$ & $?$ & $n b$ & $n b$ & $n b$ \\
1.5 & $?$ & $?$ & $?$ & 99 & 100 & 100 & $n b$ & $n b$ & $n b$ \\
2.5 & $?$ & $?$ & 98 & 98 & 99 & 99 & 99 & 100 & $n b$ \\
3.5 & 64 & $?$ & 97 & 97 & 98 & 98 & 99 & 100 & $n b$ \\
4.5 & 68 & 95 & 96 & 97 & 97 & 98 & 99 & 99 & $n b$ & \\
5.5 & 71 & 95 & 96 & 96 & 97 & 98 & 98 & 99 & 100 \\
6.5 & 75 & 94 & 95 & 96 & 97 & 97 & 98 & 99 & 100 \\
7.5 & 78 & 94 & 95 & 96 & 97 & 97 & 98 & 99 & 100 \\
8.5 & 82 & 94 & 95 & 96 & 96 & 97 & 98 & 99 & 100 \\
9.5 & 86 & 94 & 95 & 96 & 96 & 97 & 98 & 99 & 100 \\
10 & 87 & 94 & 95 & 95 & 96 & 97 & 98 & 99 & 100 \\
\hline
\end{tabular}

Table 2. Labor supply choice $(\rho=2 \%)$.

\begin{tabular}{cccccccccccc}
\hline$\sigma / \varphi$ & 0.1 & 0.2 & 0.3 & 0.4 & 0.5 & 0.6 & 0.7 & 0.8 & 0.9 \\
\hline 0.5 & $?$ & $?$ & $?$ & $n b$ & $n b$ & $n b$ & $n b$ & $n b$ & $n b$ \\
1.5 & $?$ & $n b$ & $n b$ & $n b$ & $n b$ & $n b$ & $n b$ & $n b$ & $n b$ \\
2.5 & $?$ & 100 & 99 & 99 & 100 & 100 & 100 & $n b$ & $n b$ \\
3.5 & 99 & 99 & 99 & 99 & 99 & 99 & 99 & 100 & $n b$ \\
4.5 & 99 & 98 & 98 & 98 & 98 & 99 & 99 & 100 & $n b$ \\
5.5 & 99 & 98 & 98 & 98 & 98 & 98 & 99 & 99 & $n b$ \\
6.5 & 98 & 97 & 97 & 97 & 97 & 98 & 99 & 99 & 100 \\
7.5 & 98 & 97 & 97 & 97 & 97 & 98 & 98 & 99 & 100 \\
8.5 & 98 & 97 & 96 & 97 & 97 & 98 & 98 & 99 & 100 \\
9.5 & 97 & 96 & 96 & 96 & 97 & 97 & 98 & 99 & 100 \\
10 & 97 & 96 & 96 & 96 & 97 & 97 & 98 & 99 & 100 \\
\hline
\end{tabular}

Table 3. Labor supply choice $(\rho=3 \%)$.

\begin{tabular}{ccccccccccc}
\hline$\sigma / \varphi$ & 0.1 & 0.2 & 0.3 & 0.4 & 0.5 & 0.6 & 0.7 & 0.8 & 0.9 \\
\hline 0.5 & $?$ & $?$ & $?$ & $n b$ & $n b$ & $n b$ & $n b$ & $n b$ & $n b$ \\
1.5 & $?$ & $n b$ & $n b$ & $n b$ & $n b$ & $n b$ & $n b$ & $n b$ & $n b$ \\
2.5 & $?$ & $n b$ & $n b$ & 100 & 100 & $n b$ & $n b$ & $n b$ & $n b$ & $n b$ \\
3.5 & $n b$ & 100 & 100 & 99 & 99 & 100 & 100 & $n b$ & $n b$ \\
4.5 & 100 & 99 & 99 & 99 & 99 & 99 & 99 & 100 & $n b$ \\
5.5 & 100 & 99 & 99 & 98 & 98 & 99 & 99 & 100 & $n b$ \\
6.5 & 100 & 99 & 98 & 98 & 98 & 98 & 99 & 99 & $n b$ \\
7.5 & 99 & 98 & 98 & 98 & 98 & 98 & 99 & 99 & 100 \\
8.5 & 99 & 98 & 97 & 97 & 98 & 98 & 98 & 99 & 100 \\
9.5 & 99 & 98 & 97 & 97 & 97 & 98 & 98 & 99 & 100 \\
10 & 99 & 97 & 97 & 97 & 97 & 98 & 98 & 99 & 100 \\
\hline
\end{tabular}


ages are seen from Table 1 (for $\sigma$ being in the vicinity of 3 to 4 , and for low $\phi$ values). Importantly, unknown labor supply behavior arises for the preference parameters often identified as realistic (see entries with ?s).

Remark 3. We did a sensitivity analysis, and considered the values of $\sigma, \phi$ in much finer increments. We also considered logarithmic preferences. The results of the experiments were similar to those obtained above.

Recall various retirement confidence surveys of American households reveal the majority of the population often prefer to retire around 65 - 70 years of age, and we see that very few parameters lead to such incentive. What is more troubling is that it is not clear what the labor supply would be when $\sigma$ is in the vicinity of 1 , and when $\phi$ is in the vicinity of 0.3 (Table 1). Based on the large body of evidence from the micro studies, [29] claims that $\sigma$ is close to unity. Macroeconomic studies often assume a very low degree of impatience, therefore it is not unreasonable to assume that an average discount rate might be close to $1 \%$ as in Table 1.

\section{Numerical Results Based on an Optimization Software}

We have shown that optimal intertemporal labor supply behavior is yet to be determined for a non-trivial number of conventional parameters. We tried to make our conclusions via explicit, mathematical derivations, but one can easily see that even for the basic, totally friction-free model, it is too challenging to generate all the possible solutions via a "pen-and-a-paper" method. Thus, in this section, we resort to a numerical optimization software to shed further light on the optimal decisions of the agent under the full spectrum of the model's parameters.

In particular, we use the GPOPS-II (a MATLAB) software package developed for solving multiple-phase optimal control problems using hp-adaptive Gaussian quadrature collocation methods and sparse nonlinear programming as described in [30]. We do not intend to bore the reader with the technicalities behind the software as the authors themselves have described them excellently and in detail.

For the sake of brevity, we do not show here the computational codes or all the results we have generated (though they are readily available upon request). Instead, we briefly summarize the generated results in the following remark.

Remark 4. First, GPOPS-II software confirms all our results presented in Tables 1-3. Second, for those parameters where analytically it was not possible to show the pattern of the labor supply behavior (see ?s in the above tables), we obtained the following results: The labor supply path either displays a few entries and exits to the labor market, or shows prolonged absenteeism from work (sometimes spanning decades) for no apparent reason. In most cases, the corresponding consumption path remains "deceivingly" quite smooth. It is extremely difficult to intuitively link the full spectrum of highly unusual labor supply patterns given the values of corresponding model parameters.

\section{Conclusions}

We revisit a seminal life-cycle rational model of intertemporal labor/leisure, consumption/saving choice. To our knowledge, previous studies have not systematically analyzed labor supply behavior via conventional mathematical techniques, and considered rather narrow space of preference parameters in simulation exercises. We believe that this was done to simplify the mathematics and computations involved, yet we show aforementioned simplification might leave us with many questions to answer.

We find that the above friction-free model either fits the real facts very poorly, or results in a very nonconventional labor supply choice over time which is very hard to predict a priori or intuitively interpret. Yet optimal consumptions paths nearly always remain quite smooth, almost deceiving the researcher that there should not be any "anomaly" in the labor supply path. Despite the absence of any friction or behavioral defects, rational agents often decide to frequently enter/exit the labor market, while frequently displaying prolonged voluntary absenteeism from work (sometimes spanning for a few decades), thus being completely at odds with intuition. In fact, non-standard labor supply behavior often arises for our model's preference parameters identified as realistic in various micro studies. There is an enormous amount of literature on consumption smoothing and related topics, and perhaps it is time to investigate how smooth and predictable labor supply behavior can be.

Thus, as a simple rational choice model delivers surprising labor supply decisions, we wonder whether we fully understood rational labor choice behavior to begin with, and whether more sophisticated models would be immune to the above problems once a researcher considers a full spectrum of the model parameters. Apparently, confusing labor supply patterns are a natural feature of the mathematical solution to a completely standard, intertemporal neoclassical consumption-saving/labour-leisure model that is often used in one form or another, as a 
foundational block behind many applied studies. A complete intuitive understanding of a rational, intertemporal labor supply choice even in a totally friction-free environment requires further analysis.

\section{Acknowledgements}

We are grateful to Frank Caliendo, James Feigenbaum, and the seminar participants at Deakin University and American University of Sharjah for many helpful comments and suggestions. Special thanks go to the editor and two anonymous referees, whose thoughtful suggestions have considerably strengthened the paper. All errors are our own.

\section{References}

[1] Heckman, J. (1974) Life Cycle Consumption and Labor Supply: An Explanation of the Relationship between Income and Consumption over the Life Cycle. American Economic Review, 64, 188-194.

[2] Bütler, M. (2001) Neoclassical Life-cycle Consumption: A Textbook Example. Economic Theory, 17, $209-221$. http://dx.doi.org/10.1007/PL00004098

[3] Dunn, L. (1996) Loss Aversion and Adaptation in the Labor Market: Empirical Indifference Functions and Labor Supply. Review of Economics and Statistics, 78, 441-450. http://dx.doi.org/10.2307/2109791

[4] Camerer, C., Babcock, L., Loewenstein, G. and Thaler, R. (1997) Labor Supply of New York City Cabdrivers: One Day at a Time. Quarterly Journal of Economics, 112, 407-441. http://dx.doi.org/10.1162/003355397555244

[5] Colonna, F. and Marcassa, S. (2015) Taxation and Female Labor Supply in Italy. IZA Journal of Labor Policy, 4, 1-29. http://dx.doi.org/10.1186/s40173-015-0030-0

[6] Gregory, J. and Lin, C. (1992) Constrained Optimization in the Calculus of Variations and Optimal Control Theory. Chapman \& Hall, London.

[7] Angeletos, G.-M., Laibson, D., Repetto, A., Tobacman, J. and Weinberg, S. (2001) The Hyperbolic Consumption Model: Calibration, Simulation, and Empirical Evaluation. Journal of Economic Perspectives, 15, 47-68. http://dx.doi.org/10.1257/jep.15.3.47

[8] Barro, R. and Sala-i-Martin, X. (2004) Economic Growth. The MIT Press, Cambridge, MA.

[9] Boeri, T. and Burda, M. (1996) Active Labor Market Policies, Job Matching and the Czech Miracle. European Economic Review, 40, 805-817. http://dx.doi.org/10.1016/0014-2921(95)00091-7

[10] Rönsen, M. and Sundström, M. (1996) Maternal Employment in Scandinavia: A Comparison of the After-Birth Employment Activity of Norwegian and Swedish Women. Journal of Population Economics, 9, 267-285. http://dx.doi.org/10.1007/BF00176688

[11] Wanberg, C., Kanfer, R. and Rotundo, M. (1999) Unemployed Individuals: Motives, Job-Search Competencies, and Job-Search Constraints as Predictors of Job Seeking and Reemployment. Journal of Applied Psychology, 84, 897-910. http://dx.doi.org/10.1037/0021-9010.84.6.897

[12] Taniguchi, H. and Rosenfeld, R. (2002) Women’s Employment Exit and Reentry: Differences among Whites, Blacks, and Hispanics. Social Science Research, 31, 432-471. http://dx.doi.org/10.1016/S0049-089X(02)00009-1

[13] Graversen B. and van Ours, J. (2008) Activating Unemployed Workers Works: Experimental Evidence from Denmark. Economics Letters, 100, 308-310. http://dx.doi.org/10.1016/j.econlet.2008.02.016

[14] Vandeweyer, J. and Glorieux, I. (2008) Men Taking Up Career Leave: An Opportunity for a Better Work and Family Life Balance? Journal of Social Policy, 37, 271-294. http://dx.doi.org/10.1017/S0047279407001742

[15] Tatsiramos, K. (2010) Job Displacement and the Transitions to Re-employment and Early Retirement for NonEmployed Older Workers. European Economic Review, 54, 517-535. http://dx.doi.org/10.1016/j.euroecorev.2009.10.001

[16] Messe, P. (2011) Taxation of Early Retirement Windows and Delaying Retirement: The French Experience. Economic Modelling, 28, 2319-2341. http://dx.doi.org/10.1016/j.econmod.2011.04.010

[17] Chen, J., Shao, X., Murtaza, G. and Zhao, Z. (2014) Factors That Influence Female Labor Force Supply in China. Economic Modelling, 37, 485-491. http://dx.doi.org/10.1016/j.econmod.2013.11.043

[18] Cassou, S., Gorostiaga, A. and Uribe-Zubiaga, I. (2013) Policy Effects of the Elasticity of Substitution across Labor Types in Life Cycle Models. Economic Modelling, 35, 59-70. http://dx.doi.org/10.1016/j.econmod.2013.06.021

[19] Koka, K. and Kosempel, S. (2014) A Life-Cycle Analysis of Ending Mandatory Retirement. Economic Modelling, 38, 57-66. http://dx.doi.org/10.1016/j.econmod.2013.11.042

[20] Bullard, J. and Feigenbaum, J. (2007) A Leisurely Reading of the Life-Cycle Consumption Data. Journal of Monetary 
Economics, 54, 2305-2320. http://dx.doi.org/10.1016/j.jmoneco.2007.06.025

[21] Fuster, L., İmrohoroğlu, A. and İmrohoroğlu, S. (2008) Altruism, Incomplete Markets, and Tax Reform. Journal of Monetary Economics, 55, 65-90. http://dx.doi.org/10.1016/j.jmoneco.2007.10.004

[22] Gahramanov, E. and Tang, X. (2013) Should We Refinance Unfunded Social Security? Economica, 80, 532-565. http://dx.doi.org/10.1111/ecca.12023

[23] Feigenbaum, J. (2008) Can Mortality Risk Explain the Consumption Hump? Journal of Macroeconomics, 30, $844-872$. http://dx.doi.org/10.1016/j.jmacro.2007.08.010

[24] Caliendo, F. and Gahramanov, E. (2009) Hunting the Unobservables for Optimal Social Security: A General Equilibrium Approach. Public Finance Review, 37, 470-502. http://dx.doi.org/10.1177/1091142109332053

[25] Caliendo, F. and Gahramanov, E. (2013) Myopia and Pensions in General Equilibrium. Journal of Economics and Finance, 37, 375-401. http://dx.doi.org/10.1007/s12197-011-9187-6

[26] Bagchi, S. (2011) Demographic Shocks, Retirement Decisions and Optimal Social Security. Doctoral Thesis, Utah State University, Logan.

[27] Gourinchas, P.-O. and Parker, J. (2002) Consumption over the Life Cycle. Econometrica, 70, 47-89. http://dx.doi.org/10.1111/1468-0262.00269

[28] Feigenbaum, J. (2007) Precautionary Saving Unfettered. Working Paper, University of Pittsburgh, Pittsburgh.

[29] Attanasio, O. (1999) Consumption. In: Taylor, J.B. and Woodford, M., Eds., Handbook of Macroeconomics, 1B, North-Holland, Amsterdam, 741-812.

[30] Patterson, M. and Rao, A. (2014) GPOPS-II: A MATLAB Software for Solving Multiple-Phase Optimal Control Problems Using hp-Adaptive Gaussian Quadrature Collocation Methods and Sparse Nonlinear Programming. ACM Transactions on Mathematical Software, 41, Article No. 1. http://dx.doi.org/10.1145/2558904

\section{Submit or recommend next manuscript to SCIRP and we will provide best service for you:}

Accepting pre-submission inquiries through Email, Facebook, LinkedIn, Twitter, etc. A wide selection of journals (inclusive of 9 subjects, more than 200 journals)

Providing 24-hour high-quality service

User-friendly online submission system

Fair and swift peer-review system

Efficient typesetting and proofreading procedure

Display of the result of downloads and visits, as well as the number of cited articles

Maximum dissemination of your research work

Submit your manuscript at: http://papersubmission.scirp.org/ 